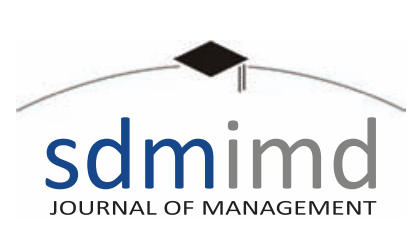

\title{
MBA Degrees Versus an Industry-Centric Managerial Certification - An Innovative Solution for Globally-Positioned Enterprises
}

\author{
Dr. Raymond Keng Wan Ng, PhD \\ Yuppies Club International Inc., USA
}

\begin{abstract}
Presently, many countries are facing challenges of continuing economic contraction, huge public debts, bankrupt governments, massive unemployment, and underemployment of young graduates and mid-career professionals, geopolitical issues and socio-economic uncertainties. At the same time, universities and institutions continue to produce legions of MBA holders to fill the global marketplace justifying the shortfall in management talents in many economies, especially the emerging markets and BRICS economies which are likely to forge continued global economic growths.

In this paper, the author investigates the macro environment, identifies the needs of today's industries, and examines the current ecosystem of the business education sphere. Special emphasis will be focused on curriculum and pedagogies review, as well as an economic justification of pursuing an MBA education against embarking a catalyst qualification intended to speed up management placements, improve return on investments of stakeholders, add value to the learning process and answers to the needs of today's industries.
\end{abstract}

Keywords: competency-based assessment, SME manager, industry, certification, SME trend, global-centric

\section{Introduction}

Since modern globalization started in the early nineties, multinationals from the United States and Western Europe have adopted a strategy of downsizing, outsourcing and off-shoring to cut operational costs, build new market shares and enhance profits. Governments in many countries have also shown similar behaviours through rapid privatisations, downloading strategic assets and de-regulations of state-owned enterprises. While these activities are put in place, adjustments in many economies have taken place resulting in early retirements, massive layoffs of factory workers, executives and corporate managers, migration of jobs from the richer economies to the emerging markets and so forth. The collective impact of this phenomenon had created a new trend pattern in seeking economic survival as most big-sized enterprises consolidated and those individuals affected by layoffs started their own need-based startups. Hence, we see a growing trend across the world today that the business world is now make up of more than 95\% of Micro, Small \& Medium Sized Enterprises, (MSME's).

From a human capital perspective, industry leaders and global management consultancies like McKinsey \& Company and NASSCOM had also expressed concerns about more than $90 \%$ of university graduates not able to meet industry expectations and poor in application of knowledge and execution of tasks with little supervision. The competence gap between what universities and business schools teach and what is needed in today's industries is widening.

Currently, there is also an absence of an exact definition of Small and Medium Sized Enterprise (SME) across 
the globe and different countries define this class with slightly different standards for example, annual revenue below a certain dollar amount or below a certain number of employees. The present author would take the standard of SMEs as, all business entities employing less than 20 employees and an annual revenue below 10 million in US dollar denomination, which help us define the boundaries for deliberation on a universe comprising more than $80 \%$ of the universe of small and medium sized enterprises. To frame our discussions further, MBA and similar or equivalent post-graduate programs are considered to have similar definition and the world today produces more than 1.5 million MBA graduates, based on a universe of more than 14000 business schools. This will permit us to set the agenda and stay focused on our discussions.

\section{A Relevant Literature Review}

Mintzberg (2004), a McGill University (Canada) Professor asserted that business schools are usually premature for students with little or no related working experience and hence do not interface well into industry criteria to gain employability. Pfeiffer (2002) from Stanford Graduate School of Business (USA) further expressed concerns of the quality of MBA graduates, placing emphasis on economic justifications on the part of employers to argue his case. Though caused a 'business school' industry shakeup, it has also pondered many stakeholders to rethink about the value-add of MBA graduates to the bottom line. Bok (2003), a former President of Harvard University pointed to similar directions, highlighting the unjustifiable costs charged by private online business education as well as expressing concerns on universities trying to earn quick profits at the expense of quality of face-to-face instructions. Hamada (2000), ex-Dean of University of Chicago had explicitly expressed concerns in the over-built MBA industry more than a decade ago.

In India, Dholakia (2011), ex-director of the renowned Indian Institute of Management at Ahmadabad had similar concerns over legions of poor quality of MBA (PGMP) holders permeating the Indian market and Starkey and Titatsoo (2007) similarly, state that most MBA programs lack the academic rigor as well as relevance to the corporate world. Their collective advises have contributed to the author's motivation to create a more sustainable model applicable, affordable and accessible to all stakeholders globally.

To support this thesis, employing communities worldwide have also raised concerns and rejected many MBA graduates for new entrant positions in multi-national corporations, stating poor competence to meet targets, incapable to initiate and lead projects as well as requiring intensive supervision to name a few limitations.

These evidences of poor quality are even more apparent in recent years due to the cutbacks of budget in the higher education sector by governments across the world. The outcome had further dampened the affordability factor, created more marketing hypes and contributed to more corruptions within the business school ecosystem.

\section{Research Methodologies}

In this paper basically, empirical approaches and scrutinizing of authoritative journals and publications were employed to gather relevant information. Interviewing B-Schools students and graduates of recent years had also helped to formulate part of the thesis.

Typically, to produce an MBA graduate, the following processes are taken:

1. Candidate applies, prepare and attempt Graduate Management Admission Test or equivalent exams.

2. After passing, apply to the business school of choice.

3. Pass a selection interview and start the learning journey (2-year tenure).

4. Embark about 10 Core Courses (to master the fundamentals of business principles, theories and concepts) in Year 1.

5. Specialized in functional areas like Finance, Operations Management, Marketing,ITManagement or Entrepreneurship during one-half in Year 2.

6. Engage in Industry Internship for 6 months in Year 2.

7. Pass all modules (usually by written form).

8. Engage in more than 100 Case Studies (through team work). 
9. Submit a Capstone Thesis/ Project (Depending on individual business school policy).

10. Conferment of degree.

The Association to Advance Collegiate Schools of Business (AACSB) - the world's oldest business school accreditation body states that to qualify for its accreditation, business schools would need to fulfill a minimum of 30 semester hours in teaching the relevant core subjects besides having to comply with other standards like percentage of full-time faculty etc. Most of the requirements for AACSB accreditation are targeted at the infrastructural support, faculty profile, and students' academic ability analogous to the ISO 9000 certification. Though it will help MBA aspirants to shortlist the school of choice, the system does not include any components to attest level of knowledge required to perform any work-based tasks, as well as requiring students to demonstrate any industry knowledge and business skill set directed at a particular industry. Till date out of 14000 business schools worldwide, only 655 and 138 institutions have received the AACSB and the European Quality Improvement System (EQUIS) accreditation respectively, making up less than $5 \%$ of the business school ecosystem.

\section{Research Objectives}

This paper attempts to examine the current practices in the MBA educational processes. Every year, more than 250000 students with an undergraduate degree attempt the GMAT Examination to enter U.S. business schools as well as reputed universities in the European Union and a few in Asia-Pacific. In India, business school entrance examinations are conducted periodically to accept students to MBA or equivalent programs like the 2-Year Postgraduate Diploma in Management (PGMP in short) and applications for such programs have been stratospheric attaining figures of more than 200000. In China, the demand for management education has also been rising since the last ten years. Universities in every major city are offering MBA programs and related business disciplines in finance, operations management, marketing, applied economics and information technology management to name a few. In Singapore, Malaysia, Thailand, Philippines and Indonesia, there is also lack of providers of MBA educational opportunities. As a matter of fact, there are several universities with global branding such as INSEAD (France), University of Chicago Business School, Babson College, Lancaster University (UK), University of Nottingham (UK), ESSEC Business School (France), S.P Jain School of Management (India) amongst others that already have outreach campuses in the Asian region.

Despite the availability of learning platforms, there is a growing concern of the quality of learning outcomes, and more importantly, how MBA holders are able to contribute to higher productivity and profits in the workplace in an ethical and socially responsible manner. This requirement is even more sought-after after the 2008 sub-prime mortgage crisis that resulted in the world wide financial crisis.

Adding to these, the current sovereign debt crisis in the European Union impacting Portugal, Ireland, Italy Greece and Spain further pound the economic, social and political stability of the entire region. Even United Kingdom, France, Belgium and other intended candidatures of the E.U. membership are also impacted negatively in this crisis.

From an institutional perspective, most governments have resorted to cutting educational budget, increased tuition fees and commercialized business education, especially to overseas' students. This behavior had unintentionally resulted in questionable quality of the MBA delivery process.

Hence, the paper intends to discuss some of these causes and effects, looking into the process of the traditional MBA program as well as its strengths and weaknesses in meeting industry's expectations and the learners' individual post-graduation business competence. The author would also propose solutions to fill the needs of stakeholders in today's globally competitive environment.

\section{Examining the Profile of Today's MBA Applicants}

Till date, the criteria of MBA aspirants in most of the B-Schools are still set at minimum standards such 
as an undergraduate degree and a reasonably high GMAT scores or its equivalent (i.e. (C.A.T. in India). The higher quality ones like the Harvard, Stanford, MIT or IIMs in India with limited seats may introduce another layer of quality assurance by interviewing those shortlisted to match with their global diversity standards which would help sustain or enhance current ranking.

However, in the interests of increasing university endowment, increasing costs and sustainability of institutions, many universities had relaxed their criteria and adopted a less stringent admission policy. Hence, students with little or no related industry experience were also admitted. This has resulted in many students conferred with an advanced business degree but not employable due to a lack of industry competence.

In essence, an MBA holder is usually trained to spearhead divisional projects as a Strategic Unit Manager (SUM), a General Manager of a Small \& Medium Sized Enterprise or one aspiring to becoming an entrepreneur during or immediately after the MBA learning process. However, most business schools are still falling short in enticing industry experts to becoming academics and their overdependence of age-old case study materials usually adopted wholesale from clearing house like Harvard Business Press and its European counterparts had contributed to the competence gap. In short, most MBA holders are not mature enough to take on the role even as entry-level executives.

\section{The Entrance Examination}

GMAT and its likes are only effective to gauge the academic ability of individuals in their basic communication and English language, mathematical and analytical skills. As grades from those examinations could also be inflated through expending in preparatory classes conducted by education providers like Thaler and Koval (2009); it is definitely not a good gauge of management competence required by MBA holders. One can only ascertain that the MBA graduates are able to comprehend the learning materials and pass the assessments embedded in the curriculum. There is also a concern of the contents being tested as some components favour those that are familiar with area culture, geography and political happenings and others may be too quantitatively-designed. In this respect, it is not a level playing field for all test-takers and thus, undemocratic in its offerings.

\section{The "Not-So-Transparent" Ranking Game}

In a world of intense competition, ranking by institutions, associations and publishers were used as a tool and strategy to bring more revenue as well as reputation to the organizers/publishers. However, users (including MBA aspirants) are usually ignorant about the methodology employed in how business schools are being ranked as different organizers had placed different weights on each component.

At present, the major ranking publishers include: Business week, Wall Street Journal, Financial Times (UK), QS University Ranking, The Economist (UK) and U.S. World News and Report. In Asia, Business India and Shanghai Transport University along with several others have embarked on the ranking game.

MBA aspirants are usually ignorant of the components like, diversity of faculty members and students, as well as components like students' satisfactions and the efforts to entice more student applications, which could lead to a corrupted rank. Furthermore, there are also obscurities in the heterogeneous sampling size taken, the employability factor and the hard-to-compare research capabilities within each institution. All these create difficulties for individuals to form a fact for prudent business school selection.

\section{The Competitive Accreditation Game}

At present, there are two business school accreditation bodies, based in the U.S. namely, The Association to Advance Collegiate Schools of Business (AACSB) and the Accreditation Council for business schools and Programs (ACBSP) that are recognized by the U.S. Department of Education in granting professional accreditations to business Schools. As the process is a voluntary one, not all accredited universities have embarked this journey as there are recurring costs 
involved. However, it is usually perceived by most MBA aspirants as better quality assurance and also heavily marketed by the accredited institutions that they are one up when differentiating their quality and commitment in terms of faculty profile, learning environmental, student cohort and infrastructural back-up. Students are also placing a bet that employability as well as their starting salary would be enhanced by attending such accredited institutions.

In the European Union, the EQUIS Accreditation Scheme has been heavily touted and in the United Kingdom, the Association of MBA (AMBA) is another player in offering third-party quality assurance to verify institutional support system ideal for business education.

Their work had also spread across continents and today, top-tier business schools like IIM, Ahmadabad and a couple of others in India, Singapore and China are recipients of such attestations. Other institutions are probably, not ready for such scrutiny which needs lots of political will or only keen to embark local accreditation offered by government vehicles like the NAAC and AITCE and other newly established accreditation agencies like the International Accreditation Organization based in the United States where, Bangalore University is a recipient amongst a few.

From a student's perspective, the lack of international accreditation may be a hindrance to global career mobility when one embarks an international career across border. And from an institutional angle, the lack of this component in place may lead to a reputational squeeze and its ability to differentiate and compete with others for better quality students and a higher profit margin.

Having stated its importance from a branding perspective, MBA aspirants should be mindful that a quality system in place does not equate a competent learning outcome. Accrediting agencies rarely expend a period long enough to examine the classroom delivery, interact with students - current and those graduated after a couple of years, interview other stakeholders like their current or previous employers of graduates of the institutions. In essence, it should be incorporated as one of several parameters to research and publish for ranking purposes and selection of business school.

\section{The Curriculum Defects}

Traditionally, most business schools were structured as a two-year process. Students usually embark a generic core subjects and concentrate on one or two majors like Finance, Marketing, Operations Management and IT Management in one-half of the second year and the next half engaging industry internship-which is another 'hard-to-measure' component as there is currently no set global and national standards in how it shall be programmed, assessed and reviewed.

With today's economic environment of tuition fee inflation as well as poor job market, business schools in the United States and some in the European Union have started to be more creative and flexible to shorten the MBA process by redesigning one-year MBA program instead of the traditional two year tenure. From a cost and time-to-market perspectives, it actually makes economic sense as long as curriculum are reengineered prudently.

The consideration to shorten and trim the overall period is based on various economic factors; college costs affordability, opportunity costs, as well as availability of new technologies to facilitate the learning process versus what was not available 100 years ago where MBA first originated in the West (pioneered by University of Pennsylvania Wharton School of Management).

There are also arguments that some core subjects had already been taken by MBA aspirants coming from a business and economic discipline and hence are unproductive to be duplicated in the curriculum as the MBA degree is actually designed as a second degree for which students from all disciplines are eligible to join.

Adding to the above, there are also concerns in what business schools teaches, the ratio of theories and experiential learning, the currency of contents and its relevance in today's business environment, especially after the dot-com bust and the 2007 global financial crisis. It still looms the global job market today. The systemic effect from the latter had caused corporate 
behavior to change how businesses are operated. Hence, unless business schools start reviewing existing curriculum and pedagogical approach and incorporate currency, it is deemed as a 'lagging' mechanism to counteract the new challenges, brought by globalization, sovereign debt crisis and the rich-poor imbalances.

There are also observations that students were given too many tutorials to handle during their learning tenure. This approach had unintentionally created a knowledge vacuum amongst students on what is happening outside the b-school sphere. It has created a 'knowledge vacuum' on current world affairs and contributed a wider competence gap amongst many MBA holders to be placed into industries to solve business problems, employing strategies and tools of the yesteryears.

What B-Schools should do and teach is to adopt a justin-time content creation approach tapping materials from major international news media and global publications like, The Wall Street Journal, Business week, Bloomberg, Fast Company, South China Morning Post to name a few. Contrary to age-old textbooks and journals, it is a safer bet to impart industry competence and derive a higher applied learning outcome.

\section{The Pedagogical Defects}

Today, most business schools still adopt the teach-andtest approach. Students attend about an hour's session for each subject and engage with group work and tutorial. The ratio of professor to students' ratio varies amongst institutions and across borders. A one guru to more than a hundred student ratio is not uncommon. This setting had also resulted in a low level of authenticity of intended learning outcomes especially on the application of knowledge transfer into today's work environment. What are usually gained are theories and concepts untested for real-time application.

The model of teaching is also vital to affect a desired learning outcome. Only some innovative business schools have taken the initiative to restructure weak processes to improve resource synergy and industry relevancy. As witnessed, many institutions still adopt the one professor to one classroom approach. There are many reasons for this setting. Perhaps, the business school is trying to stretch resources to optimize bottom-line or the guru community is too arrogant and complacent in adopting the 'little kingdom' mentality. This model lacks synergy as most MBA holders today are expected to work in SMEs where, multi-tasking and the need to offer quick and sustainable solutions are demanded. When knowledge is compartmentalized, MBA students would have harder time trying to get their act together. This is a shortcoming for business education providers and likely to produce sub-standard graduates.

\section{Assessment Methods}

The traditional MBA Programs still emphasizes on rote learning adopting mostly teach and test method to verify learning. At the time of writing, there is no global standard to ascertain the individual MBA student's industry competence. Standards set by individual business schools are either too generic or too obscure. Results could also be inflated or harmonized in the interests of growing institutional endowment. Hence, it is difficult for potential employers from different parts of the globe to accurately measure whether the candidate's ability fits the roles demanded.

\section{Poor Regulatory and Institutional Policies}

In practice, most business schools seldom want to fail candidates not meeting the academic standards. Should too many experience the failing grades, it will impact business schools negatively in their recruitment in the years ahead and it is also taboo to the institution's reputation going forward.

The absence of a national or a global standard for assessing business competence makes it even more obscure to measure post-learning competence. This is a process deficiency as the business school literally transfers the risks of its 'product' to potential employers. From the moral standpoint, it is unethical though legal as Business Schools are supposed to help in developing future ethical business leadership. Conferring an advanced business degree is analogous to awarding a qualified driver, a license to drive on the road. However, 
there are currently no institutional policies exercised by business schools worldwide to retract degrees on those graduates who later committed crimes of moral turpitude, evidently experienced during the 2007 U.S. Sub-prime mortgage crisis as well as the European Union sovereign-debt crisis and rampant corruption practices perpetually permeating many emerging economies till date.

The proliferation of business schools especially in emerging economies like, India has to do with lax policies and corruption practices. Business schools had became a product for mass consumerism and many are literarily 'selling' MBA degrees like commodities, especially those that had franchised their offerings, penetrating the market with different permutations and heavy marketing hypes. This practice had further confused the consumer (MBA aspirants and their sponsors) and also had marginalized other well-intended Business Schools.

In essence, there is a social responsibility obligated by regulators and all business school boards to demand the retraction of conferred MBA testimonial as well as blacklisting the holder when, a willful crime of economic nature is committed.

\section{A Possible Solution-Certified Global SME Manager Designation (CGSMEMgr)}

With the advent of rapid globalization and market liberalization, the macro-trend is towards a larger community of SMEs make-up in both developed and developing economies. This is clearly evident in the United States, the European Union as well as China, India and the emerging markets in Latin America, African States and ASEAN nations where, SMEs contributed to the largest new employing group while multinational corporations continue downsizing and outsourcing.

Take the Indian scenario, several observations and facts can be detected. They include:

1. SMEs as a sector contributes more than $40 \%$ of Indian total export
2. It is the major employing sector for college graduates after globalization and market liberalization of early 1990s

3. Multinational corporations are constantly outsourcing the SMEs

4. B-Schools seldom teach the 'how-to' to students to globalize an SME.

5. B-Schools seldom teach how SME to seek funding from local and global private equity, business angels and external commercial borrowing.

6. B-Schools overemphasized teaching of concepts and principles in managing large Western-styled corporations which is quite difficult to apply in today's prevalent SME environment.

7. India has approximately 13 million SMEs today producing about 8000 products and employing 41 million people but only contributed to only about $9 \%$ of GDP. Hence, there is ample space for strategic intervention to beef up the 'competence gap' and one such initiative is to build a talent pool to engage global markets through the proposed certification.

8. According to recent report published by ASSOCHAM, SMEs still faces the squeeze in local financing which impedes its growth. Hence, equipping the knowledge of fund raising from the global capital markets is essential for both potential and practicing SME Managers.

9. The 'how' and 'where' to solicit international business contracts and where to locate the sources for procurement and new markets were seldom taught in B-Schools. Other soft skills needed to build a sustainable SME Sector were also seldom incorporated in most B-School curriculum.

10. The aftermath of the dot-com era and the more recent global financial crisis had changed the game plan of the global business community. Legal knowledge among SME Managers is mostly weak as most were not taught in B-Schools and new knowledge in cyber laws and e-commerce expertise are alien to many.

The above scenarios are also shared in many other economies including the United States and the European Union as well as the BRICS nations, though each also has its unique idiosyncrasies. 
In designing this qualification, the author has considered the major impediments in the design, delivery and assessment components of the current business school model (though not all are the same) and matching what is needed in today's complex and fastchanging business world. To disclaim, the solutions are not foolproof but establish a framework for more deliberations and further refinement to addressing the current gap. The proposed framework and justifications are as follows:

\section{A Certification Program Tailoring to World-Class SMEs}

As Small \& Medium Sized Enterprises (SMEs) may not have the capacity to scale in domestic markets due to its size and resources, the actors (owner-managers and executives) must be equipped with adequate knowledge and skill sets to access foreign markets. At this time of writing, there is a lack of adequate content incorporated in the learning process across nations to teach learners how to access a global market for specific products and industry. And failing to impart these competences would likely restrict business executives and entrepreneurs from accessing global markets prudently.

\section{Why Global?}

Most SMEs today must survive and thrive with a globally-needed product or service. To limit their market focusing on only domestic, state or national level may not be economically viable for their longterm good. This is especially, so for highly-intensive knowledge-based enterprises which are able to serve a global customer base from the beginning without having to overstretch their human and financial capital too much.

At this point, there is absence of focus in most business schools which still employ the 'Big Corporation', Model to teach MBA students who like to work in an SME environment after graduation. Hence, the body of knowledge to be imparted should emphasize business strategies and tools to access specific foreign markets.
The pedagogy employed should also incorporate globetrotting market feasibility studies and target specific industries.

\section{Curriculum Planning: Matching the Skill-set required with the Roles Required of Global-Centric SME Managers}

As the mechanics and economics are vastly different when managing SMEs and MNCs (Multi-national Corporations), it is vital that the knowledge and skill sets to be mastered must be reformed from an industry perspective. Generally, the Elements of Competence to be assessed include:

1. Leading and managing a small workforce from 5 to 20 employees

2. Managing a Virtual Team-locally or globally

3. Hands-on operations management

4. Negotiate with Vendors and Strategic Partners

5. Market to customers - local and overseas

6. Establish business contracts

7. Solicit Agencies, Distributorship, Global Franchise and License

8. Access foreign markets

9. Manage financing - Equity and Debt

10. Design incentives for employees and agents

11.Build global network

12. Design \& Initiating Quality Processes

13. Train employees

14. Solve Customer Problems

15. Build Global Brands

16. Create, Protect and Position Intellectual Properties

17. Strengthen Corporate Governance

18. Measure Productivity and Profitability

19. Conduct Feasibility Studies

20. Manage Projects

21. Comply with legal regulations

22. Architect Social and Mobile Network Strategies

23. Identify new business opportunities

24. Establish Growth Plan

25. Perform Financial Analysis

26. Design an Innovation Plan

27. Assessing Competition

28. Launch New Venture 


\section{Formulate Global Business Plan}

Each candidate is required to demonstrate before a panel of experts - the elements of competence specified in an Assessment Agreement. A final interview via online or on-campus is mandatory.

\section{Body of Knowledge Needed}

1. Industry-specific knowledge

2. Global Market Understanding

3. Legal and Taxation Strategies

4. Mechanics of World Trade Organization and Free Trade Agreements

5. Business and Corporate Laws

6. Research Skills

7. Execute Global Sourcing

8. Incorporation of Global Business Entities

9. Positioning Global Enterprises

10. Global Business Networking

11. How to capitalize on current global events

12. Legal Knowledge: Business Law/Company Law/ Financial Law/Cyber and E-Commerce Laws

Disclaimer: The above listed is not exhaustive.

Each candidate is required to pass the knowledge test. Special emphasis will be focused on assessing the level of industry knowledge, the overall business environment, the mechanics of business, how to strategize within one's selected industry, how to position one's business from a global branding and tax-advantage perspective, how to create a global network for the SME type and how to manage risks effectively and how to domicile a company to achieve optimal global advantage just to name a few.

Contrary to the above elements and competence identified, there is an absence in business schools to confer MBA degree via competency-based learning and assessment model. The assessment of candidates on the body of knowledge based on individual interests to engage a particular industry by a panel of experts is currently absent. The panel should ideally comprise of 3 to 4 Members led by a chairperson elected by the group from both academia, industry practitioners and even government officials, to bring SME Managers standards align at a master degree level, equivalent to the United Kingdom National Vocational Qualification at Level 7.

To start this initiative, there is a need to establish a global-centric non-for-profit body, similar to the U.S. non-for-profit $501 \mathrm{C} 3$ or the United Kingdom Company Limited by Guarantee structure, where a board of advisers and board of assessors are in place with representation from all cities across the globe. This will set the tone in establishing a truly global SME Manager Industry Competency Standards.

The current MBA contents and pedagogies employed may be already redundant, costly and overpriced from the perspective of time taken to 'Manufacture' an MBA holder as well as the financial burden to expend two years against a one year industry-focused qualification assessed by industry experts with more than 10 years of related experience proposed by the author.

The Certification also includes a pre-assessment and post-assessment process-an innovation to measure the knowledge and skills level both before and after the entire learning and assessment process. Note that the emphasis here is on how to help SME Managers apply knowledge and skill sets to effect prudent enterprise.

There is also innovation by incorporating a 'Just-inTime' content development component, emphasizing on current world affairs and business thrust within one's region versus studying generic contents from college texts. Though it could be introduced as a B-School qualification, there should be flexibility to offer this certification through a combination of online and oncampus model, with the object to optimize community outreach. Candidates are expected to be disciplined and competent to manage rigorous self-learning projects and work with certified mentors throughout the learning process. A real-time innovation, productivity and Profit Enhancement Project are mandatory for as Capstone Project. All submissions would be published for stakeholders' scrutiny and endorsements, fulfilling a policy of transparency and one-world quality assurance and 
verification of competence mastered before conferring the award. These approaches will help to provide more relevance to today's SME industry needs and beef up employability of business graduates vis-à-vis the traditional MBA delivery process.

\section{Costs/Benefit Analysis}

Generally, a two-year full time MBA degree on average would cost between US\$50,000 to US\$ 197,000 at the highest end, charged by Harvard Business School. This cost did not factor in the living expenses and logistical and insurance cost.

To grow the qualification and to make it accessible, affordable, accredited and globally accepted by all SMEs, it is vital that cost to candidature and industry sponsors should make economic sense. An estimate cost per candidate to embark in this global certification should be kept below US\$ 2,000/- to entice optimal global participation if it is offered via online learning and e-assessment mode and not more than US\$ 5,000/for a one year full time on campus mode.

\section{Promote Currency of Certified Global SME Managers}

The requirement to maintain standards is to keep everyone current. All Certified GSME Managers will be required to submit an Annual Continuing Learning Report pertaining to management issues, new strategies or business opportunities occurring within one's industry. This component is to bring knowledge up to date for global sharing and compels every certified designee to think and act global. All submissions would be published online to serve as a platform for global knowledge sharing.

\section{Conclusion}

As this proposal is at a prima facie stage, more research would need to be conducted across the globe to further understand how businesses are conducted, reaching out to special interests groups like global industry associations and experts to solicit views and insights. The author also intends to explore the geopolitical issues impacting
SMEs globally and how to employ risk management strategies to help mitigate risk exposure.

At this juncture, the author's focus is on data collection and networking with relevant stakeholders including accreditation bodies, government agencies and potential candidates across the globe. The collective wisdom would help to formulate a 360 degree approach in designing and facilitating a multi-dimensional competency-based qualification which aspires to be current and dynamic.

His ultimate intent is to establish a global institute to certify global-centric SME Managers and promote a one-world SME Manager competency-based standard. This initiative would help align the current practice of heterogeneous creation of MBA holders 'manufactured' by business schools spanning across the globe. The initiative would also reduce the burden of high college debts paid by sponsors or borne by the candidates and help accelerates applied industry knowledge, research skills and managerial competence to fit this globallydynamic SME environment.

From an aspiring student's perspective, a globallyaccepted competency-based qualification guided and assessed by industry practitioners would help in enhancing career mobility for Certified Global SME Managers to work across borders once a one-world standard is recognized by all stakeholders within the ecosystem. In essence, the certification is analogous to established credentials like Chartered Financial Analyst (CFA) designation or the United Kingdom Chartered Engineer qualification and would be designated at a National Qualification Framework of Level 6 to 7, equivalent to a Bachelor degree with Honors or at Masters degree level.

\section{References}

ASSOCHAM/Grant Thornton. (2008). SMEs Have to be Smart Money Enterprises.

Kaplan Thaler, L., \& Koval, R. (2009). Making It Big by Thinking Small. The Power of Small (pp. 108-121). New York: Broadway Books.

Mintzberg, H. (2004). Managers Not MBAs. Berrett Koehler Publishers. 
Starkey, K., \& Titatsoo, N. (2007). The Business School and the Bottom Line. United Kingdom: Cambridge University Press. The Official Guide For GMAT Review (12 ${ }^{\text {th }}$ ed.). (2009). Wiley Publishing, Inc.

\section{About the Author}

Dr. Raymond Keng Wan Ng holds a Ph.D. from the University of Azteca, Mexico. He is an independent consultant and entrepreneur and is the founder of
Yuppies Club International Inc. USA, which is a Global Business Learning \& Networking Alliance. The author would like to thank all readers for their constructive feedback in advance. He is currently assuming a series of roles-being a global knowledge-based entrepreneur, author, people development specialist, business educator, investment and economic development strategist and more so a "penguin dad" and a good son based in Singapore. He can be reached at wealthconsultant@, yahoo.com 